\title{
SYNTHESIS AND CHARACTERIZATION OF CuO- ZnO NANO ADDITIVE FOR LUBRICANT
}

\author{
Buddha Kumar Shrestha, ${ }^{2}$ Hira Mani Trital ${ }^{* *}$ and Armila Rajbhandari (Nyachhyon)* \\ *Central Department of Chemistry, Tribhuvan University, Kirtipur, Nepal. \\ *** Nepal Lube Oil Ltd., Amlekhgunj, Bara, Nepal.
}

\begin{abstract}
A mixed metal oxide $(\mathrm{CuO}-\mathrm{ZnO})$ additives has been successfully synthesized in laboratory by coprecipitation technique. The optimum ratio of $\mathrm{CuO}$ and $\mathrm{ZnO}$ in mixed metal oxide was found to be 1:1. The sodium lauryl sulfate (SLS) has been used as surfactant. The obtained material was found to be crystalline having crystalline size of $18 \mathrm{~nm}$. The stretching band in FTIR spectra at around $1072 \mathrm{~cm}^{-1}$ to $750 \mathrm{~cm}^{-1}$ and around $600 \mathrm{~cm}^{-1}$ indicates the presence of $\mathrm{Zn}-\mathrm{O}$ and $\mathrm{Cu}-\mathrm{O}$ bonds. As prepared nano-particles have been used as nano additive in base oil to improve physio-chemical parameters of lubricants. The results revealed that the additive blended base oil (lubricant) has shown excellent lubrication properties. The higher kinematic viscosity of 33.0504 and 6.0158 at $40^{\circ} \mathrm{C}$ and $100^{\circ} \mathrm{C}$ respectively showed that as prepared additive blended lubricant is of ISO-32 category according to ISO grading system for lubricants. Similarly, viscosity index was found to be improved from 101 to 129 . The pour point was found to be significantly decreased from $-6^{\circ} \mathrm{C}$ to $-24^{\circ} \mathrm{C}$. So it can be used as good pour point depressant and could be used even in the extreme cold environment condition. The flash point was found to be increased from $215^{\circ} \mathrm{C}$ to $220^{\circ} \mathrm{C}$ indicating that the prepared mixed metal oxide $(\mathrm{CuO}-\mathrm{ZnO})$ acts as flash point enhancer. The copper strip corrosion rating was found to be $1 \mathrm{~b}$ for additive indicating the non corrosive nature. The absence of moisture and $\mathrm{pH}$ around the neutral range 6.18 showed the additive blended lubricant is not harmful for machinery devices.
\end{abstract}

Keywords: CuO-ZnO; Mixed Metal Oxide; Additive Blended Lubricant; Kinematic Viscosity; Viscosity Index; Flash Point; Pour Point.

\section{INTRODUCTION:}

The present century is the machinery age. All the human activities are dependent on machinery devices. Without machinery devices, one cannot survive in present world. It has got wide applications in industrial sector, communication sectors, medical sector, educational sector and transportation sectors etc. Thus machines are complimentary part of human life. One expects the machine having high efficiency, long durability and highquality performance. Unfortunately, after long time use of the machines, the performance deteriorates as a consequence of friction of two rubbing surfaces.

This sort of frictional resistance may cause wear and tear in mechanical equipment on the surfaces of moving parts and also due to on exposure to contaminants, that leads to damage of its movable parts. In such situation, highly viscous liquids are commonly used which is termed as lubricants. Only base oil lubricants are insufficient to reduce frictional resistant in machinery devices. In order to fulfill current demand of machinery devices that is reduction of friction a third body has been added in these days. Additives may be any substances which enhance properties of lubricants. Ahmad et al. 2014 has reported two types of detergent/dispersant additives ${ }^{1}$. First one is mild detergent/dispersant additives which are composed of simple hydrocarbons or ash less compounds and another is over based detergent/dispersant which are composed of calcium, barium or zinc salts of sulphonic, phenol or salicylic acids. In addition to this wide variety of additives including nano particles like $\mathrm{Cu}, \mathrm{CuO}, \mathrm{ZnO}$, $\mathrm{TiO}_{2}, \mathrm{CeO}_{2}, \mathrm{Al}_{2} \mathrm{O}_{3}, \mathrm{MoS}_{2}$, nano graphite, nano diamond, carbon nanotube, $\mathrm{ZrO}, \mathrm{LaF}_{3}, \mathrm{CaCO}_{3}$ etc. have been investigated by different scientist in the recent year ${ }^{2-21}$. Literature review showed that metallic oxide as well as mixed metal oxide additives have been successfully used by different workers. There is dearth of literature for synthesis of mixed metal oxide as lubricant additive. In the year of 2014 a mixed metal oxide additive has been prepared by Veerendra and his group ${ }^{22}$.The synthesis of $\mathrm{CuO}-\mathrm{ZnO}$ nanoparticles was done by co-precipitation method and studied the anti-wear properties, coefficient of friction and wear scar diameter of $\mathrm{CuO}-\mathrm{ZnO}$ nanoparticles blended in base oil (SAE 20W-50) at different concentrations $(0.5,1.0$ and $2.0 \%$ by wt. $)$. It was found that the $1.0 \%$ by wt. of $\mathrm{CuO}-\mathrm{ZnO}$ nanoparticle suspension in lubricant exhibited the better tribological behavior. However, the effect of mixed metal oxide on the physio-chemical properties of the lubricants has not been studied. Hence, in present study; we try to synthesis of $\mathrm{CuO}-\mathrm{ZnO}$ mixed metal oxide nanoparticles bycoprecipitation method. The prepared material will be characterized by different technique like XRD, FT-IR etc. and as prepared material will be blended with base oil (lubricant) as additive. Further physio-chemical properties of additive blended lubricant will be investigated and compared with base oil (SN-150).

\section{EXPERIMENTAL METHODS}

Materials and methods: Laboratory grade Copper sulfate pentahydrate $\left(\mathrm{CuSO}_{4} .5 \mathrm{H}_{2} \mathrm{O}\right)$, Zinc sulfate heptahydrate $\left(\mathrm{ZnSO}_{4} .7 \mathrm{H}_{2} \mathrm{O}\right)$, Sodium hydroxide, Oxalic acid, granulated AR zinc Qualigens were obtained from Thermo Fisher Scientific Pvt. Ltd, India whereas laboratory grade lauryl sodium sulfate was obtained from Titan Biotech Ltd A-902A, Riico Industrial Area, Phase 
Iii, Bhiwadi-301019 (Raj), India. The base oil SN-150 was obtained from local market.

Synthesis of CuO-ZnO mixed metal oxide: The $\mathrm{CuO}$ $\mathrm{ZnO}$ mixed metal oxide was prepared by taking equimolar mixture of $\mathrm{CuSO}_{4} .5 \mathrm{H}_{2} \mathrm{O}$ and $\mathrm{ZnSO}_{4} .7 \mathrm{H}_{2} \mathrm{O}$ in a burette and was added dropwisely to the $(0.1 \mathrm{M}) \mathrm{NaOH}$ solution containing lauryl sodium sulfate as capping agent. The solution was stirred continuously with the help of magnetic stirrer. The precipitate was obtained which was then filtered and washed with dehydrated ethyl alcohol and distilled water alternatively for five times. After proper washing, the precipitate was calcined to $600{ }^{\circ} \mathrm{C}$ for 6 hours in a muffle furnace ${ }^{22}$.

Characterization of CuO-ZnO: The crystal structure and average crystalline size was measured by BrukerD8 Advance X-ray Diffractometer using monochromatized $\mathrm{Cu} K \kappa\left(\lambda=1.54060{ }^{0} \mathrm{~A}\right)$.Metal-oxygen stretching vibrations of the sample were examined by SHIMADZU Fourier Transform Infrared Spectrometer. The $\mathrm{CuO}: \mathrm{ZnO}$ ratio in the mixed metal oxide was determined by complexometric titration as well as $\mathrm{pH}$-metric titration.

Preparation of additive blended lubricant: The 1\% (wt/wt) additive blended base oil was prepared by mixing surface modified $(\mathrm{CuO}-\mathrm{ZnO})$ mixed metal oxide and base oil (SN-150 density $0.861 \mathrm{~g} / \mathrm{ml})$. It was stirred for 6 hours with $2000 \mathrm{rpm}$ by using elite motor so that mixed metal oxide was dispersed uniformly without any settlement.

Physiochemical characterization of additive blended lubricant: Kinematic Viscometer (STANHOPE SETA LIMITED) has been used to investigate viscosity. To investigate Flash Point, Cleveland Open Cup has been employed. In the same way, digital refrigerator (EIE Instrument PVT.LTD.) was applied to study the pour point of oil. Constant Temperature Bath (EIE Instrument PVT. LTD) has been used to test the corrosion. Test methods employed for the study of physio-chemical parameters shown in Table 1.

Table 1: Test methods employed for the study of physio-chemical parameters

\begin{tabular}{|c|c|c|}
\hline S.N. & Test Parameter & $\begin{array}{l}\text { ASTM } \\
\text { Method }\end{array}$ \\
\hline 1 & Kinematic Viscosity at $40^{\circ} \mathrm{C}(\mathrm{cSt})$ & D 445 \\
\hline 2 & $\begin{array}{l}\text { Kinematic Viscosity at } 100^{\circ} \mathrm{C} \\
(\mathrm{cSt})\end{array}$ & D 445 \\
\hline 3 & Viscosity Index & D 2270 \\
\hline 4 & Pour Point $\left({ }^{\circ} \mathrm{C}\right)$ & D 97 \\
\hline 5 & Flash Point $\left({ }^{\circ} \mathrm{C}\right)$ & D 92 \\
\hline 6 & Emulsion test at $54{ }^{\circ} \mathrm{C}$ & D 1401 \\
\hline 7 & $\begin{array}{l}\text { Corrosion test (copper strip test) } \\
\text { at } 50{ }^{\circ} \mathrm{C}\end{array}$ & D 130 \\
\hline
\end{tabular}

\section{RESULTS AND DISCUSSION}

X-ray analysis: The $\mathrm{XRD}$ pattern of as prepared $\mathrm{CuO}$ $\mathrm{ZnO}$ mixed metal oxide is shown in Fig. 1. The diffraction peaks were well defined and good agreement with JCPDS card No. 36-1451 for ZnO and JCPDS card
No. 89-5899 for $\mathrm{CuO}$. In the figure, the sharp diffraction peaks $32.5^{\circ}$ at $2 \theta, 35.5^{\circ}$ at $2 \theta, 38.8^{\circ}$ at $2 \theta$, and $48.7^{\circ}$ at $2 \theta$ are assigned for tenorite structure of $\mathrm{CuO}$ whereas; peaks $31.7^{\circ}$ at $2 \theta, 34.6^{\circ}$ at $2 \theta, 36.3^{\circ}$ at $2 \theta$ and $47.6^{\circ}$ at $2 \theta$ are assigned for zincite structure of $\mathrm{ZnO}$. Similarly, peaks $31.8^{\circ}$ at $2 \theta, 34.8^{\circ}$ at $2 \theta$, and $35.5^{\circ}$ at $2 \theta, 36.6^{\circ}$ at $2 \theta$ and $38.6^{\circ}$ at $2 \theta$ are assigned for $\mathrm{CuO}-\mathrm{ZnO}$ mixed metal oxide raw.

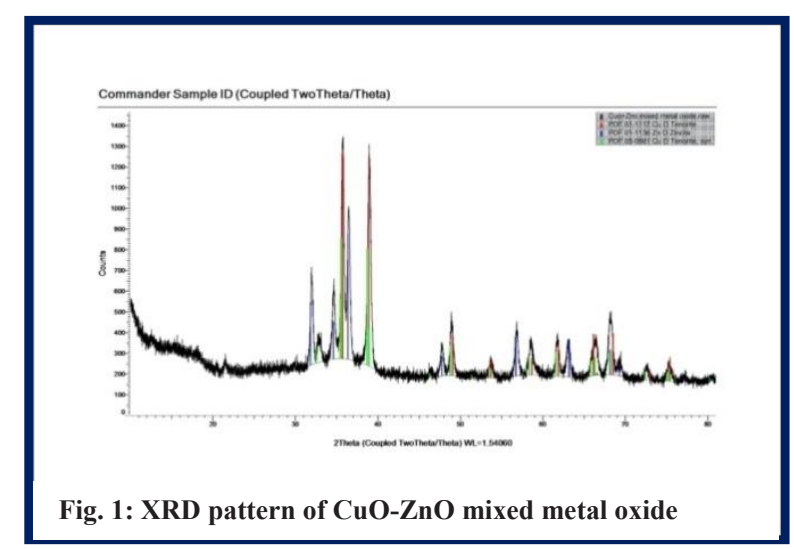

The sharp diffraction peaks indicate for the crystallinity of the material. The average crystalline size of the mixed metal oxide is also calculated from the most intense peaks using Debye-Scherrers's equation and was found to be 18 $\mathrm{nm}$. The XRD pattern and crystalline size are quite comparable with reported value ${ }^{23}$.

Fourier Transform Infrared Spectroscopy (FT-IR): The FT-IR spectrum of $\mathrm{CuO}-\mathrm{ZnO}$ mixed metal oxide is shown in Fig. 2.

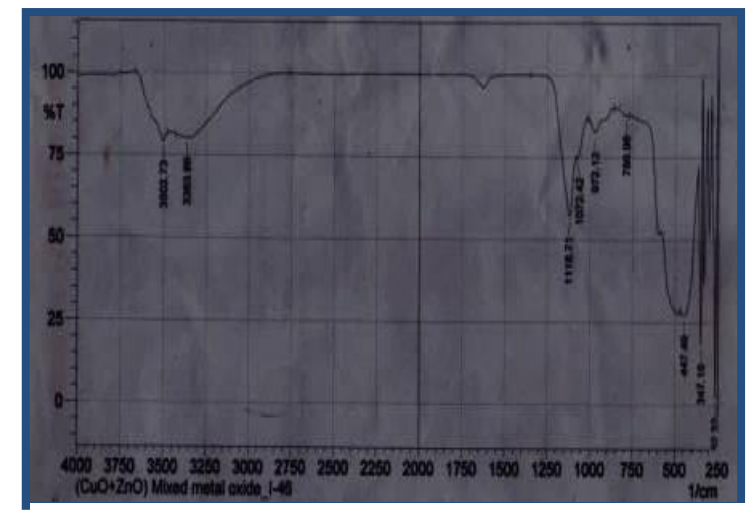

Fig. 2: FT-IR Spectrum of $\mathrm{CuO}-\mathrm{ZnO}$ mixed metal oxide

The weak and broad bands around 3250-3550 $\mathrm{cm}^{-1}$ and $1600 \mathrm{~cm}^{-1}$ were observed which indicates the stretching band of hydroxyl groups. Similarly, weak vibration band at $1600 \mathrm{~cm}^{-1}$ could be seen which indicates the presence of little water absorbed on the surface of metal oxide. A peak around the $1118 \mathrm{~cm}^{-1}$ was obvious which revealed the stretching band of $\mathrm{C}-\mathrm{H}$ vibration. One can also see the $\mathrm{Zn}-\mathrm{O}$ stretching band within the range of $1072 \mathrm{~cm}^{-1}$ to 750 $\mathrm{cm}^{-1}$ whereas $\mathrm{Cu}-\mathrm{O}$ stretching band could also be seen around $600 \mathrm{~cm}^{-1}$. These bands were in agreement with bands reported in the literature ${ }^{23}$

Determination of Composition of $\mathrm{Cu}$ and $\mathrm{Zn}$ in mixed metal oxide: The composition of copper and zinc in the $\mathrm{CuO}-\mathrm{ZnO}$ mixed metal oxide has been determined by complexometric titration and $\mathrm{pH}-$ metric titration methods. The results obtained are shown in Table 2 . 
Table 2: Results obtained by complexometric and pH metric titration methods

\begin{tabular}{|l|l|c|c|c|}
\hline S.N. & \multicolumn{1}{|c|}{ Method } & $\begin{array}{c}\text { zinc } \\
\text { (moles) }\end{array}$ & $\begin{array}{c}\text { Copper } \\
\text { (moles) }\end{array}$ & $\begin{array}{c}\text { Ratio in } \\
\text { moles(zinc : } \\
\text { copper })\end{array}$ \\
\hline 1 & $\begin{array}{l}\text { Complexometric } \\
\text { titration }\end{array}$ & 0.0025 & 0.0026 & $1: 1.04$ \\
\hline 2 & $\begin{array}{l}\text { pH- metric } \\
\text { titration }\end{array}$ & 0.0027 & 0.0022 & $1: 0.81$ \\
\hline
\end{tabular}

When ratio of the amount of copper and zinc were calculated it was found to be approximately (1:1) (Table 2 ). From the result, it can be ensured that the prepared mixed metal oxide contended copper oxide and zinc oxide in 1:1 molar ratio.

Study of physio-chemical parameters of base oil (SN 150) and additive blended lubricant

Kinematic Viscosity: The kinematic viscosity of base oil (SN-150) without additive was obtained. Similarly, additive blended lubricant at $40{ }^{\circ} \mathrm{C}$ and $100{ }^{\circ} \mathrm{C}$ were also noted and are given in the Table 3 . The results were then compared and are presented in the bar graph (Fig. 3). From the bar diagram, it can be seen that in both cases, the kinematic viscosity was found to be decreased with increase in temperature. This might be due to the weakening of inter-particle and intermolecular adhesion forces. Furthermore, it can also be seen that the kinematic viscosity was found to be higher in case of additive blended lubricant than that of base oil without additive. This may be due to fact that when with the nanoparticles are added in base oil, the internal shear stress of the lubricant rises as a consequence the viscosity increased notably.

Table 3: Kinematic Viscosity of Base oil (SN-150) and additive blended lubricant at $40^{\circ} \mathrm{C}$ and $100^{\circ} \mathrm{C}$

\begin{tabular}{|c|l|c|c|}
\hline S.N. & \multicolumn{1}{|c|}{ Sample } & $\begin{array}{c}\text { K.V. at 40 } \\
\text { (cSt) }\end{array}$ & $\begin{array}{c}\text { K.V. at } 100{ }^{\circ} \mathbf{C} \\
(\mathbf{c S t})\end{array}$ \\
\hline 1 & Base oil (SN 150) & 29.30 & 5.19 \\
\hline 2 & $\begin{array}{l}\text { Additive blended } \\
\text { lubricant }\end{array}$ & 33.05 & 6.02 \\
\hline
\end{tabular}

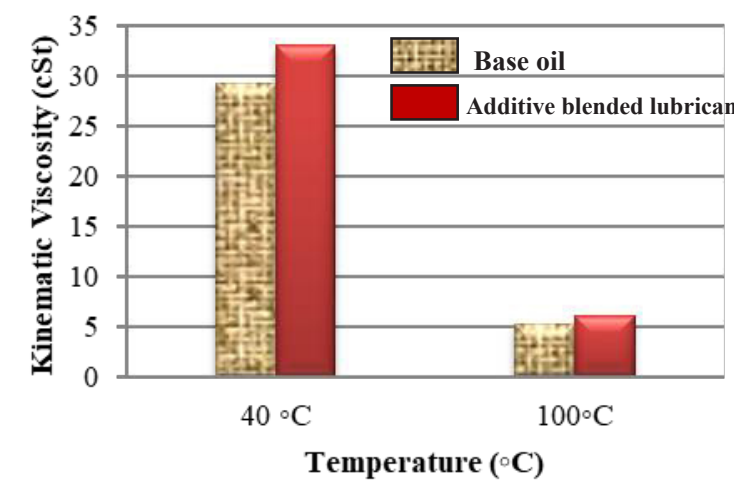

Figure: 3 A bar diagram showing the comparison of Kinematic viscosity of Base oil (SN-150) and additive blended lubricant at $40{ }^{\circ} \mathrm{C}$ and $100{ }^{\circ} \mathrm{C}$.
In addition, from the obtained value of kinematic viscosity at $40{ }^{\circ} \mathrm{C}$ and $100{ }^{\circ} \mathrm{C}$ base oil (SN-150) was categorized as ISO-22 whereas, additive blended lubricant was categorized to ISO-32 according to ISO grading system for lubricants. Thus it can be seen that as additive blended lubricant was found to be higher grade.

Viscosity Index: The viscosity index of base oil (SN150) and additive blended lubricant are determined on the basis of ASTM viscosity index table and was found to be 101 and 129 respectively. It has presented in bar graph (Fig. 4). From the Fig.4 one can observe the higher viscosity index of additive blended lubricant.

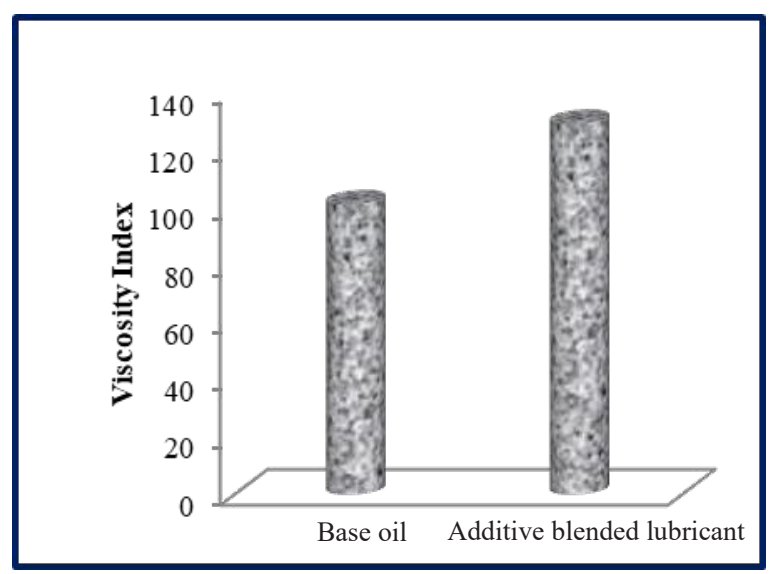

Fig. 4: A bar diagram showing the comparison of viscosity index of base oil ( $\mathrm{SN}-150)$ and additive blended lubricant

Table 4: Viscosity index of base oil ( $\mathrm{SN}-150)$ and additive blended base oil lubricant

\begin{tabular}{|c|l|c|}
\hline S.N. & \multicolumn{1}{|c|}{ Sample } & $\begin{array}{c}\text { Viscosity } \\
\text { Index }\end{array}$ \\
\hline 1 & Base oil (SN 150) & 101 \\
\hline 2 & Additive blended lubricant & 129 \\
\hline
\end{tabular}

Pour Point: Table 5: Pour point of base oil (SN-150) and additive blended lubricant

\begin{tabular}{|c|l|c|}
\hline S.N. & \multicolumn{1}{|c|}{ Sample } & $\begin{array}{c}\text { Pour Point } \\
\left({ }^{\circ} \mathbf{C}\right)\end{array}$ \\
\hline 1 & Base oil (SN 150) & -6 \\
\hline 2 & Additive blended lubricant & -24 \\
\hline
\end{tabular}

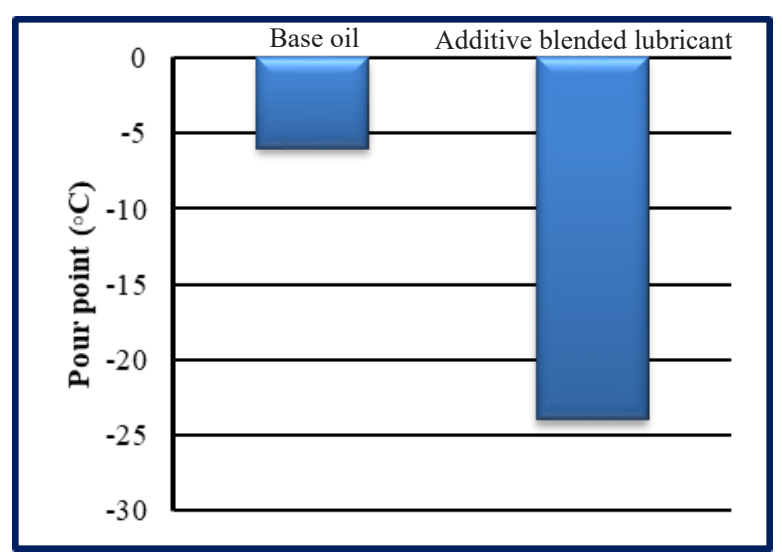

Figure: 5 A bar diagram showing the comparison of pour point of base oil (SN-150) and additive blended lubricant. 
The pour point of base oil was investigated. Then the effect of additive on pour point of base oil was also observed and results are presented in bar graph (Fig. 5). As can be seen in the bar diagram, the pour point of base oil is found to be $-6^{\circ} \mathrm{C}$ while pour point of additive blended base oil was found to be $-24^{\circ} \mathrm{C}$. It showed that pour point is significantly changed on additive blended lubricant which is the positive indication of good property of lubricant.

Flash Point: The flash point of base oil was obtained and the effect of additive on flash point of base oil was also observed and results are shown in bar diagram (Fig. 6).

Table 6: Flash point of base oil (SN-150) and additive blended lubricant

\begin{tabular}{|c|l|c|}
\hline S.N. & \multicolumn{1}{|c|}{ Sample } & $\begin{array}{c}\text { Flash Point } \\
\left({ }^{\circ} \mathbf{C}\right)\end{array}$ \\
\hline 1 & Base oil (SN 150) & 215 \\
\hline 2 & Additive blended lubricant & 220 \\
\hline
\end{tabular}

It was found that the addition of $1 \%$ nano additive to the base oil causes an increase in flash point by $2.32 \%$ in comparison to base oil. It may be due to increase thermal conductivity as reported in literature ${ }^{8}$. Here the increase of thermal conductivity occurred due to presence of extra material or additive on base oil which consequently resist against the fire. In addition to this, presence of extra material or additive which is nonvolatile leads to less amount of vapors get evaporated during flash point examination.

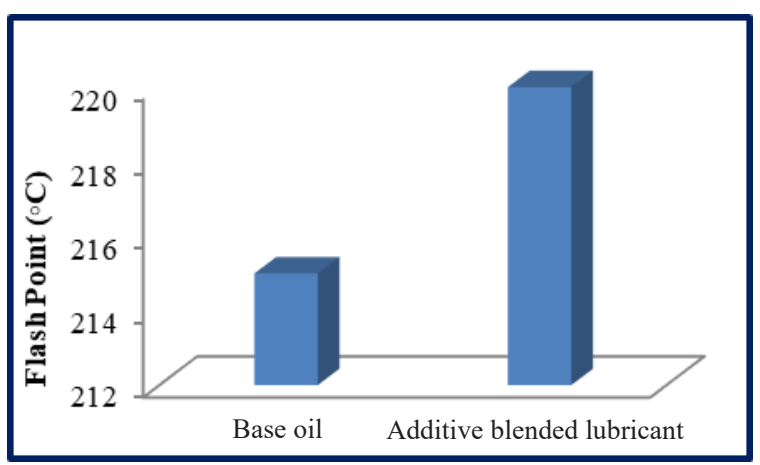

Fig. 6: A bar diagram showing the comparison of flash point of base oil ( $\mathrm{SN}-150)$ and additive blended lubricant

Emulsion Test: The separation of water and additive blended base oil at $54^{\circ} \mathrm{C}$ after the thirty minutes is shown in Fig.7. Here one can see the complete separation of water and additive blended lubricant in Fig.7.

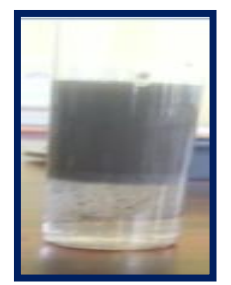

Fig. 7: Separation of water and additive blended lubricant at $54^{\circ} \mathrm{C}$ after the 30 minutes

Corrosion Test (Copper Strip Test): The copper strip corrosion test results are shown in Table 7 . The results showed that the corrosiveness of base oil and additive blended lubricant both reached a rating of $1 \mathrm{~b}$ in ASTM standard D 130-12.

Table 7: Copper strip corrosion tests of base oil ( $\mathrm{SN}-150)$ and additive blended lubricant

\begin{tabular}{|c|l|c|}
\hline S.N. & \multicolumn{1}{|c|}{ Sample } & $\begin{array}{l}\text { Copper strip } \\
\text { corrosion, rating }\end{array}$ \\
\hline 1 & Base oil (SN 150) & $1 \mathrm{~b}$ \\
\hline 2 & Additive blended lubricant & $1 \mathrm{~b}$ \\
\hline
\end{tabular}

\section{CONCLUSION}

The $\mathrm{CuO}-\mathrm{ZnO}$ mixed metal oxide nanoparticles can be prepared in the laboratory and can be used as lubricant additives. All the physio-chemical parameters; viscocity, viscocity index, flash point, pour point of the additive blended lubricant was found to be improved than base oil without addition of the additive. The results revealed that physio-chemical properties of additive blended lubricant meet the ISO-32 grade lubricant.

\section{ACKNOWLEDGEMENTS}

One of the authors Budha Kumar Shrestha is thankful to Tribhuvan University, Nepal Lube Oil Ltd. Amlekhganj, Bara for providing laboratory facilities to carry out the research work and also thankful to University Grants Commission (UGC), Nepal for thesis support grants, Department of Plant Resources (DPR) and National Academy of Science and Technology (NAST) for recording FT-IR and X-ray respectively.

\section{REFERENCES}

1. Ahmed N. S., Nassar A. M., Abdel Y. K., Abdel Y., El-Shazyl R., J. App. Chem., 2014. 7(12): 56-67.

2. Zhou J., Yang j., Zhang W., Liu W., Xue Q., Mat. Res. Bull., 1999. 34(9): 1361-1367.

3. Zhou Z., Wu Z., Zhang Z., Liu W., Dang H., Wear, 2001. 249(5-6): 333-337.

4. Bakunin V. N., Suslov A. Y., Kuzmina G. N., Parenago O. P., J. Nano. Res., 2004. 6: 273-284.

5. Bahadur S., Sunkara C., Wear, 2005. 258(9): 1411-1421.

6. Battez A. H., Rico J. E. F., Arias A. N., Rodrguez J. L. V., Rodrguez R. H., Fernandez J. M. D., Wear, 2006. 261: 256-263.

7. Battez A. H., Gonzalez R., Felgueroso D., Fernandez J. E., Fernandez M. R., Garcia M. A., Wear,2007. 263: 1568-1574.

8. Wu Y., Tsuia W., Liu T., Wear,2007. 262: 819-825.

9. Ahmadi H., Ettfagi E., Rashidi A., Mohtsebi S., Alaei M., Int. J. Indus. Chem., 2013. 4:28. http://www.industchem.com/content/4/1/28

10. Thottackkad M. V., Perikinalil R. K., Kumarapillai P. N., Int. J. Prec. Eng. \& Manuf., 2012. 13(1): 111-116.

11. Battez A. H., Viesca J. L., Gonzalez R., Blanco D., Asedegbega E., Osorio A., Wear, 2010. 268: 325-328.

12. Bhaumik S., Prabhu S., Singh K. J., Adv. Trib., 2014. 2014: 1-8.

13. Ghaednia H., Jackson R. L., Khodadadi J. M., J. Exp. Nanosci., 2015. 10(1): 1-18.

14. Jianhua Q., Yu Z., Lingling W., Jinjuan X., C. Petro. Process.\& Petrochem. Tech., 2011. 13(3): 69-73.

15. Rashin M. N., Hemalatha J., Int. Sch. \& Sci. Res. \& Innov., 2012. 6(4): 386-390.

16. Pisal A. S., Chavan D. S., Ird Ind., 2014. 3(2): 34-38.

17. Patil S. J., Patil D. P., Shrotri A. P., Patil V. P., Int. J. Mech. Eng., Tech., 2014. 5(11):120-129.

18. Baskar S., Sriram G., Trib. Indus., 2014. 36(2): 127-133.

19. Kalkada S. B., Nair K. P., Patil K. R., Int. J. Eng. Sci. \& Tech., 2014. 6(1): 34-42.

20. Bhaumik S., Pathak S. D., Trib. Indu., 2015. 37(2): 196-203.

21. Trajano M. F., Moura E. I. F., Ribeiro K. S. B., Alves S. M., Mat. Res., 2014. 17(5): 1124-1128.

22. Veerendra M. G., Kumar A., Int. J. Innov. Res. Science, Eng. \& Tech.,2014. 3(6): 13964-13970.

23. Ashok C. H., Rao K. V., Chakra C. H. S., J. Adv. Chem. Sci., 2016. 2(2): 223-226. 